\title{
Approaching Value for Money to assess viability of Public-Private partnership projects
}

\author{
Dinh Thi Thuy Hang \\ Nghe an College of Economics \\ Vietnam \\ Hangdtt.edu.vn@gmail.com
}

Abstract. The aim of this paper is to evaluate whether decision-making to pursue a Public-Private partnership model is feasible to finance a project. In order to clarify this issue, this paper carries out an analysis based on an objective method, which is quantitative Value for Money (VFM) assessment. A case study of Trung Luong-My Thuan project in Vietnam is employed to explore the validity of the method. The research result proves that there is 99 percent probability that PPP is an appropriated model to implement this project. Additionally, the stimulated VFM output is positively sensitive to construction cost overrun risk, while it is negatively sensitive to traffic demand inaccuracy.

Keywords: Public-Private partnership (PPP), Value for Money (VFM), Trung LuongMy Thuan, Monte Carlos Simulations (MCS), Vietnam.

JEL Classification: L32, L33

\section{INTRODUCTION}

For many decades, PPP has played a pivotal role in the development of road infrastructure projects in many countries, particularly developing ones. The widespread use of the PPP approach could be explained by the fact that the demand for new infrastructure still remains one of the greatest challenges in many countries (ESCAP, 2011). Since the capacity of traditional forms of public procurement and state budgets are insufficient for executing needed many projects, a PPP has become an attractive alternative for infrastructure financing.

Nevertheless, some debatable questions still remain in relation to the decision on whether to adopt PPP or the conventional public delivery model. Most of the debates center on how to evaluate such decision-making process. As an example, the National Council for Public-Private Partnerships (2012) argues that one effective method for evaluating the potential benefits involving PPP is to conduct a VFM assessment, a process that facilitates the comparison of the cost of the PPP approach with that of conventional methods. It is argued that such an analysis could provide policymakers with a quantitative tool that would help them select the course of action that leads to the most desirable outcome.

The aim of this paper is to assess the suitability of PPP for a particular project with a use of VFM assessment in terms of quantitative approach, which includes the following three main sections. It begins 
with a literature review of value for money assessment approach. It then points out methodology and case study applied throughout this research. Next, it focuses on key findings of this research. Finally, limitation and suggestions for future researches will be given account of.

\section{LITERATURE REVIEW}

Morallos and Amekudzi (2008) argue that quantiative VFM assessment as "a methodology that compares the PPP bid with a hypothetical scenario called the public-sector comparator (PSC)" (Morallos \& Amekudzi, 2008, p.115). Additionally, the Government of India (2010) states that a quantitative VFM test "compares the estimated cost of procuring the project in the public sector with the estimated cost of procuring it as a PPP" (Government of India, 2010, p.13). This contention also reflects the view in Partnerships British Columbia (2010), where quantitative VFM is defined as "compares the preferred PPP approach to a traditional procurement method" (Partnerships British Columbia (2011, p.7). Another definition in World Bank (2013) emphasize that quantitative VFM "involves a comparison of the "valuefor-money of a proposed PPP (or actual bids received) with a Public Sector Comparator-that is, a model of the project if implemented through traditional public procurement" (World Bank, 2013, p.14). Based on these definitions, it is straightforward to see that a quantitative VFM involves a comparison of the values associated with the PSC with the values associated with the PPP approach.

Fundamentally, the conventional computation of the PSC is based on the total net present value of the following four components - the raw PSC, the competitive neutrality, the transferred risk and the retained risk. However, a potential weakness of the PSC accounting approach is the explicit omission of financial costs. Most of people misunderstood that the use of state budget is free. But in fact, this source is limited. In order to finance a specific project, public sector could mobilize capital from the issuance of national government bonds. Then, they have to pay interest rate for creditors. In this regard, Tsamboulas et al. (2013) notes that the government's payments for the construction and operation of transport projects may lead to a financial burden, "either because it borrows the money or because these funds could have been used for other public purposes". Therefore, it is argued that the costs of financing should be reflected in the PSC calculation.

Regarding the cost of PPP, the basic and prevalent approach involves the use of the bid price. However, a problem with this approach is that the actual PPP price cannot be made available until the bidding stage, which is an advanced stage of the procurement process. The policy planner has to select, much earlier, the procurement method that would be used for a specific project. This means that, the VFM cannot be calculated at the planning stage, when the private sector has yet to submit its bid price. The only way to overcome this problem is to estimate the bid price likely to be submitted by the private sector, in other words, "shadow bid pricing".

Essentially, the concept of shadow bid pricing was introduced by Infrastructure Ontario, which is also called the adjusted shadow bid price (ASB). Despite the fact that the use of this approach helps to overcome the above-mentioned problem, its use still needs further refinement. In this regard, Tsukada (2015) has identified some difference between the shadow bid price (SBP) and the adjusted shadow bid prices (ASB). According to Tsukada (2015), the SBP is an effort to estimate the bid price likely to be submitted by the private sector. Meanwhile the ASB does something similar, however, it is designed for the calculation of VFM by enabling a like-to-like comparison between PSC and PPP. For this reason, the ASB is calculated by adding the retained risks to the SBP. Tsukada's approach is not a criticism toward Infrastructure Ontario, but an effort to clarify the difference between the raw PPP price and the adjusted PPP price for the purpose of calculating VFM. 
A major contribution of the methodology proposed by Tsukada (2015) lies in the modification of the traditional VFM approach in a manner that is applicable to BOT type of PPP. This is due to the fact that the existing VFM guidelines appear to be primarily intended for the unitary payment type of PPPs in which the costs are mostly paid by the government on annuity or installment basis.

Unique elements of Tsukada's approach in the calculation of VFM for the BOT type PPPP project are as follows:

Revenue should be explicitly estimated for both the PPP and the PSC (since most VFM guidelines do not explicitly require the estimate of the revenue, an important element of the BOT type of PPP)

Financing costs need to be included in both the PPP and the PSC (most VFM guidelines do not require financing cost to be included in the PSC)

Return on investment is to be included in the PPP, which is an important element (since it would correspond to the transferable risk in the PPP)

Distinctions should be made between the SBP and ABP, the latter of which is not exactly the bid price likely to be submitted by the private sector.

In order to ensure the estimation of VFM, this research adapts the revised formula of PSC and SBP.

\section{METHODOLOGY}

A sensitivity analysis and Monte Carlo simulations are applied in this research. To be precise, sensitivity analysis is carried out to measure the stochastic uncertainty of the factors (such as the risks of construction cost overrun, traffic demand shortfalls and inflation) that influencing the VFM in the project.

Alternatively, Monte Carlo simulation is used to simulate the changes in VFM in respect of the movement in the uncertain inputs. In order to use the MCS for the computation of the VFM of the project, the following four stages involved: (1) the determination of the key uncertain input variables, (2) the identification of the probability distribution of the key input variables and the resulting simulation, (3) the estimation of the PSC cash flow and that of the SBP, and (4) the generation of the VFM distribution output

\section{CASE STUDY}

The Trung Luong-My Thuan Expressway is a BOT toll road project that involved a subsidy from the Vietnamese government. In 2009, the Trung Luong-My Thuan expressway was originally sponsored by the Bank for Investment and Development of Vietnam (BIDV), with a total investment of VND 28 trillion (the equivalent of USD1.4 billion). The road was designed to 8 lanes. However, two years after the implementation of the project, the BIDV decided to return it back to the government of Vietnam due to it being unable to raise the investment capital needed. The government received the project and then transferred its operation to the Ministry of Transportation in 2011.

According to Decision 2035/TTg-KTN of the Vietnamese prime minister issues on October 14, 2014, the Vietnamese government decided to pursue a BOT model as a means to attract new investments from private firms into the project. Currently, the project is under the construction phase of the BOT model under new private investors. However, debates on the rightness of the selection of the most suitable procurement option for the project are still on going. While some argue it is better to use a BOT scheme to implement the project, others have also argued that the project should be implemented via government direct investment. In this regard, using a VFM analysis, this paper examines the validity of both sides of the debate on which procurement model best suits the project.

The primary objectives of the project are to shorten the travel time from Ho Chi Minh City to the Mekong Delta provinces, to contribute to the promotion of economic and social development of the region, and to reduce heavy congestion on Highway 1. The first point of the project is at the Than Cuu Nghia 
$(\mathrm{Km} 49+620)$ intersection, which belongs to the Ho Chi Minh City -Trung Luong Expressway, and the endpoint is at the intersection with National Highway $30(\mathrm{Km} 100+750)$.

The key features of the Trung Luong-My Thuan Expressway is summarized as following:

Location: Ho Chi Minh City - Tien Giang province (South of Vietnam)

Length: $54.3 \mathrm{~km}$ (4 lanes)

Construction cost: VND 12,616.95 billion (USD 630 million)

Construction duration: 4 years (2015-2019)

Operation period: 29 years $(2019-2048)$

\section{FINDINGS AND DISCUSSION}

\subsection{Determination of SBP}

In order to build the cash flow of the SBP, the key variables are extracted from the data source of the feasibility study on the Trung Luong- My Thuan Expressway project, summarized as follows:

(a) The total estimated investment capital for construction of the project is VND 12,616.95 billion. This will be distributed at $18 \%, 29 \%, 31 \%$, and $22 \%$ every year during the construction period.

(b) The BOT finance structure: the debt and equity ratio of the project is, respectively, $89.49 \%$ and $10.51 \%$. The debt mobilized from banks is VND 1,993 billion in the first year, VND 3,211billion in the second year, VND 3,432 billion in the third year, and VND 2,436 billion in the fourth year. The payback begins on the fourth year and will be repaid each year in the loan term of 24 years with a $9.7 \%$ interest rate.

(c) Expected interest of equity is $11.05 \%$.

(d) The corporate tax rate is $20 \%$.

(e) The concession term is 33 years.

(f) The number of traffic vehicles is forecasted to be 20,166 PCU in the year 2019.

(g) The initial toll of a PCU is set at VND 1,000 per km, which is predicted to increase $18 \%$ once every three years.

\subsection{Determination of PSC}

- Raw costs under the PSC

With regards to the capital cost of the PSC, including design and construction costs, the acquisition of land, and the acquisition of plans and equipment, the same values as the SBP apply because there is not available data regarding the proposed cost from the public sector in this case. Regarding the maintenance cost of the PSC and the management cost of the project during the operation stage, it depends on the Circular 10/2010/TT-BGTVT of the Ministry of Transport, dated October, 2010, which states the "the management and maintenance of roads indicate the particular ratio of each item in the maintenance cost". Accordingly, the general maintenance cost of the project is comprised of three components: periodic maintenance costs, special maintenance costs, and upgrade costs. The annual cost of maintaining the road during the operation stage is estimated based on a proportion of the construction cost at $0.5 \%$. The cost for retaining a good level of service for the road is defined as the special maintenance cost, which is conducted once every 4 years with a 5\% proportion compared to the construction cost. Finally, the upgrade cost is to repair the road, accounting for $42 \%$ of construction cost, which is implemented once every 12 years.

- Financing cost under the PSC 
It is hypothesized that the government mobilizes a project's capital investment through the issuance of long-term Vietnamese national bonds. According to the State Bank of Vietnam (2014), the interest rate of the ten-year government bond is $6.38 \%$ per year. This same rate is utilized to compute the financing cost component of the PSC in the case study of Trung Luong-My Thuan Expressway project.

- Revenue under the PSC

The computation of the revenue under the PSC is based on the user fees, which of course depends on the traffic demand and the price of the toll fees. Due to a lack of data on the forecasted traffic volume under the PSC, the estimated traffic volume under the PSC is assumed to be identical with the forecasted traffic volume under the PPP. Likewise, the toll fee is estimated with reference to the Circular No 159/2013/T'TBTC of the Ministry of Finance, which guides the "collection, payment, management, and use of road-use tolls for the payback of the road construction investment capital". It regulates that the minimal toll per PCU is VND 15,000; which is amounts to VND 276 per $\mathrm{km}$ under the assumption that the length of the road is $54.3 \mathrm{~km}$.

- Setting the discount rates

To compute the net present cost of the project implemented as a conventional procurement, the interest rate of the risk-free rate will be utilized to discount the cash flow during the whole life of the project.

\subsection{VFM computation}

Table 1

Comparison of the PSC and SBP

(Unit: billion $\mathrm{VND}^{*}$ )

\begin{tabular}{|l|c|c|}
\hline Items & PSC & SBP \\
\hline Outflow (A) & $23,022.29$ & $20,717.70$ \\
\hline Inflow (B) & $2,817.23$ & $7,745.83$ \\
\hline Net present of cash flow (A) - (B) & $20,205.05$ & $12,971.87$ \\
\hline VFM (PSC-SBP) & \multicolumn{2}{|c|}{$7,233.20$} \\
\hline
\end{tabular}

Note: $*$ VND $1=$ USD 0.00005

Source: Author's result

Table 1 shows the comparison of the whole costs of the Trung Luong-My Thuan project between the case of PPP scheme and a traditional delivery, revealing that the government's spending in the project of the PPP scheme is expected to be VND 12,971 over the 33 year concession period, while the spending of the conventional delivery is estimated to be VND 20,205 billion. As a result, the added value the PPP model provides VFM is VND 7,233 million compared to the traditional procurement. It means that the PPP scheme is more feasible than public sector procurement to finance the project.

\subsection{Output simulation}

A Monte Carlo Simulation with 10,000 iteration was performed to generate the distribution of the VFM for the project. Palisade's @Risk software (version 7.5) was then used to perform the simulations. Figure 1 shows the results of 10,000 trials of MCS, suggesting that the mean value of the VFM and standard deviation is, respectively, about VND 8,551 billion and VND 4,058 billion. Additionally, the value of the VFM outcome is distributed between VND 1,325 billion and VND 14,125 billion with the probability of 92.5 percent. Also, figure 2 characterizes the cumulative probability of the VFM indicator of the project, 
revealing that the probability of VFM being positive is $99 \%$. It implies that the BOT model is preferred to a traditional delivery in order to implement the Trung Luong-My Thuan Expressway project.

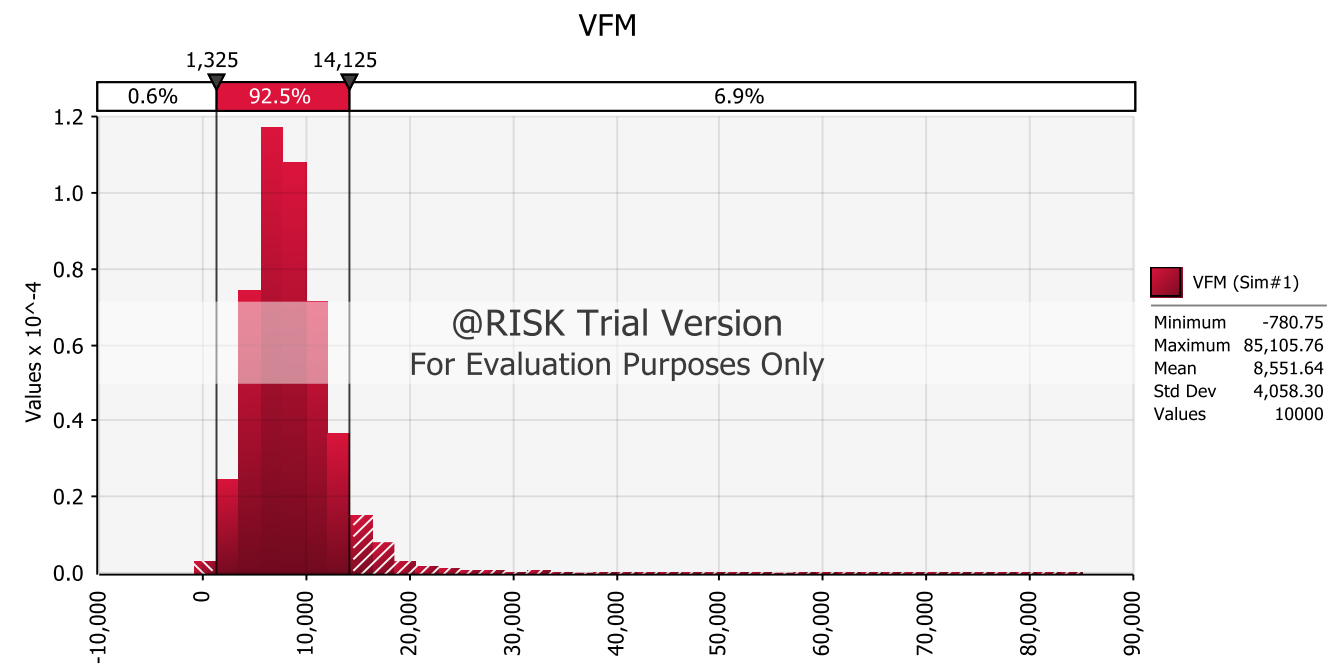

Figure 1. Distribution for the project's VFM

Source: Author's result

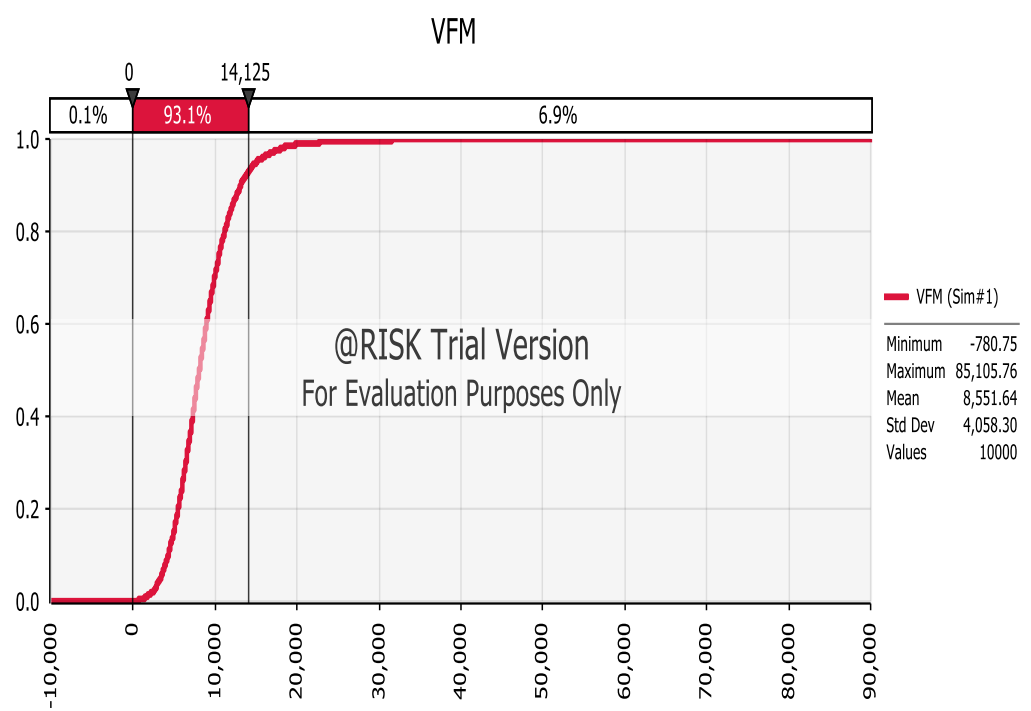

Figure 2. Cumulative probability of VFM

Source: Author's result

Although there are many variants for VFM, one of the variables that impact the VFM is the PSC toll. In order to have understanding on the effect of an alternative PSC toll being used, this research simulated the VFM outcome for two different PSC toll levels. The first is a simulation of VFM with the PSC toll at VND 276/km/PCU, while the second is a VFM simulation with the toll at VND 2,100/km/PCU. The two levels are assumed based on the Vietnamese regulation documents. In particular, according to the Circular 159/2013/TT-BTC of the Ministry of Finance dated in 2013, the minimal toll per PCU is VND 276 per $\mathrm{km}$. Meanwhile, given the Circular 35/2016/TT-BGTVT dated in 2016, the maximum toll per PCU is VND 2,100 per $\mathrm{km}$. Figure 3 shows the VFM simulations of selecting alternative PSC toll levels. The red shadow area shows the distribution of VFM as the PSC toll is VND 276/km per PCU, revealing that the probability 
of VFM being larger than zero is $99 \%$. In this case, the PPP model is better than public finance. Meanwhile, the green shadow area represents the probability distribution of the VFM as the PSC toll is VND 2,100/ $\mathrm{km}$ per PCU, suggesting the probability that VFM being positive is $9.3 \%$. It implies that, in this case, conventional delivery is more favorable than a PPP scheme. It is currently clear that a higher PSC toll will reduce the annual cash flow of a PSC, so it could make the traditional procurement cheaper than the PPP model.

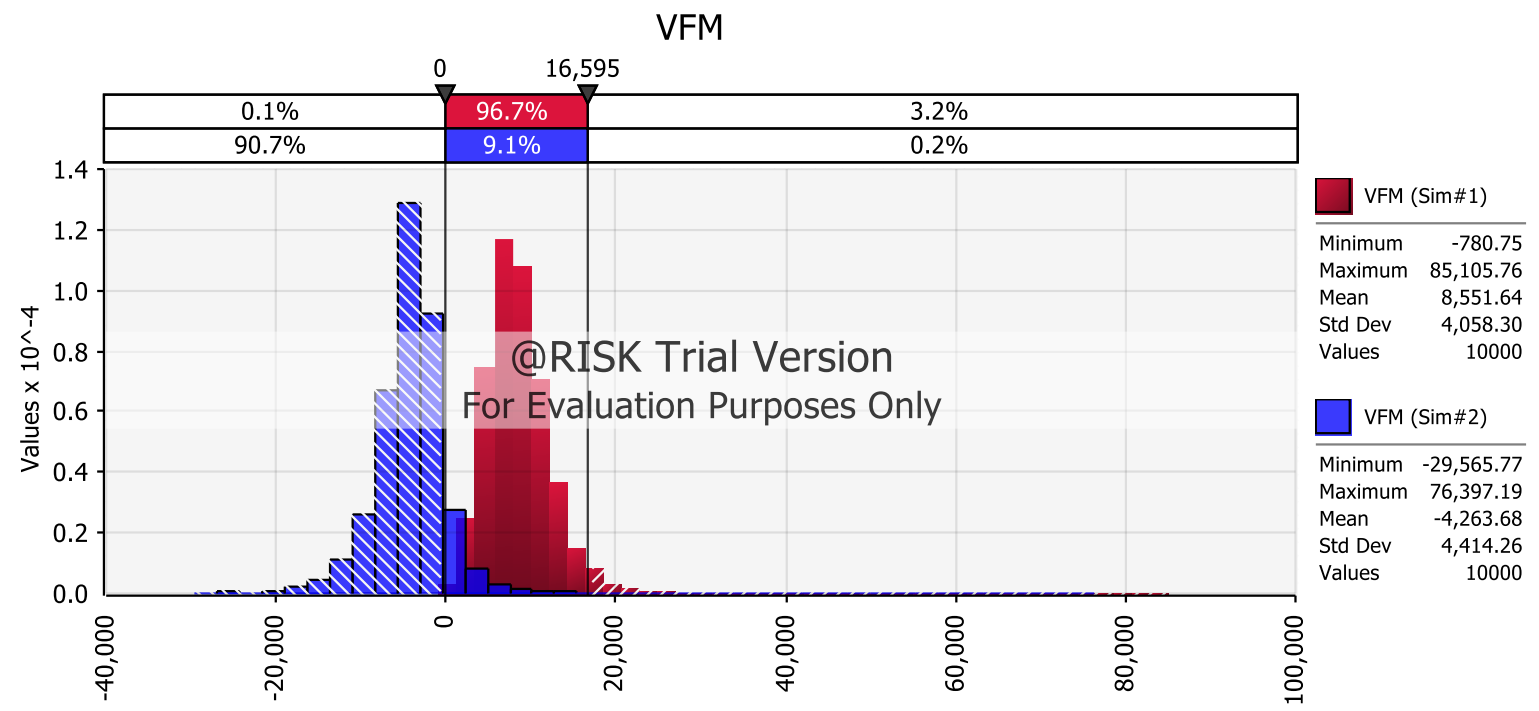

Figure 3. Distributions of VFM with alternative PSC toll level

Source: Author's result

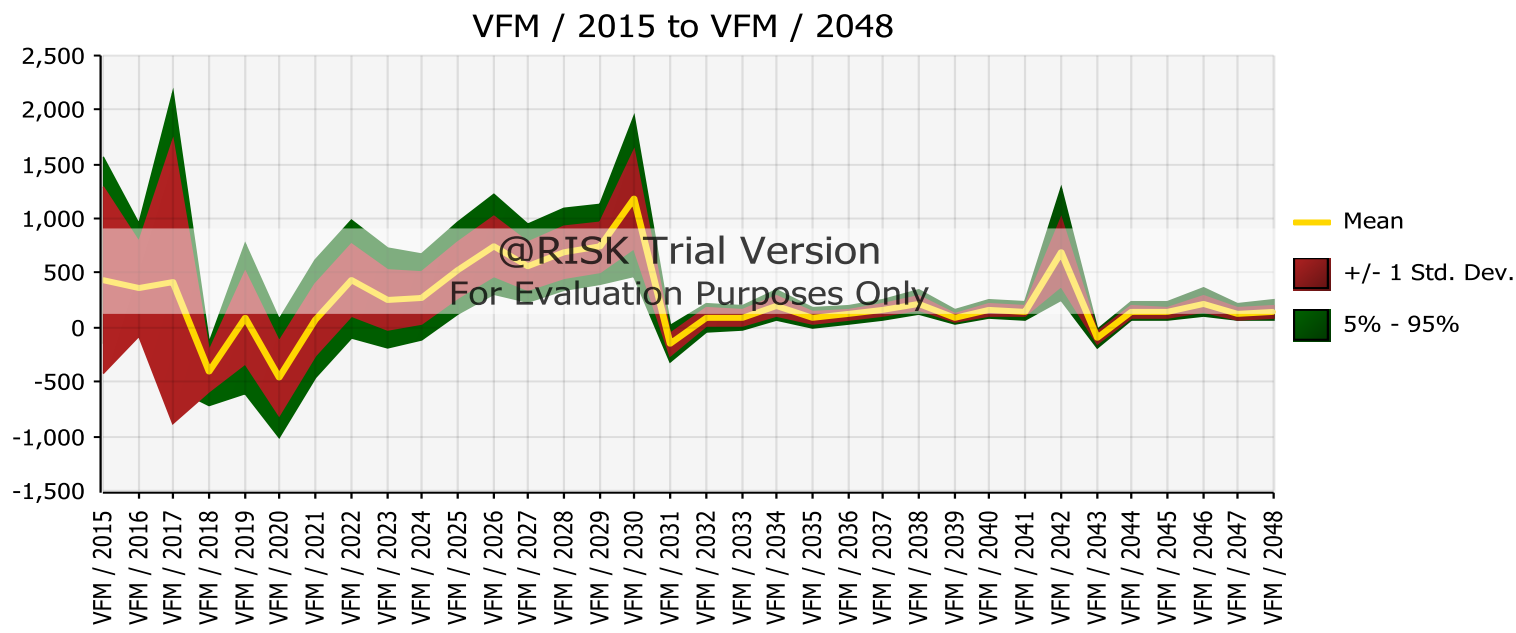

Figure 4. Summary trend of VFM

Source: Author's result

Figure 4 summarizes the distributions generated for the value of the VFM range, which allows us to know how the VFM of the Trung Luong-My Thuan project are changed from 2015 to 2048. As can be seen, the cash flow of the VFM is positive during the whole life of the project except in the years 2020, 2031 and 2043. For example, the cash flow of the VFM in the first few years is nearly VND 500 billion, and is likely to face the relegation in the fourth year. Further, the annualized cash flow of VFM during 2021 and 2030 is 
more than VND 200 billion. However, it may drop to more than VND-100 billion in the year 2031. Once again, it rises gradually during the period of the year 2032-2048. In general, the PPP model can cut more cost for the government than public sector procurement in both the construction phase and the operation phase.

\subsection{Sensitivity analysis}

Figure 5 displays the sensitivity tornado graph of the VFM, which confirms that how much percentage of the variance in the output is derived from the input variable. The $\mathrm{X}$-axis represents the variation in the outcome value, while the $\mathrm{Y}$-axis characterizes each input variable. As can be seen, the construction cost overrun risk contributes $36.81 \%$ to the variation in VFM. Meanwhile, the traffic demand inaccuracy makes up only $0.86 \%$ of variability of the VFM. In addition, the tornado graph allows us to identify which larger uncertainty factor influences the VFM of the project. Particularly in this case, the construction cost inaccuracy has the biggest effect on the output of VFM. It means that as more construction cost inaccuracy is transferred under the PPP, the value of the VFM of this project may be improved.

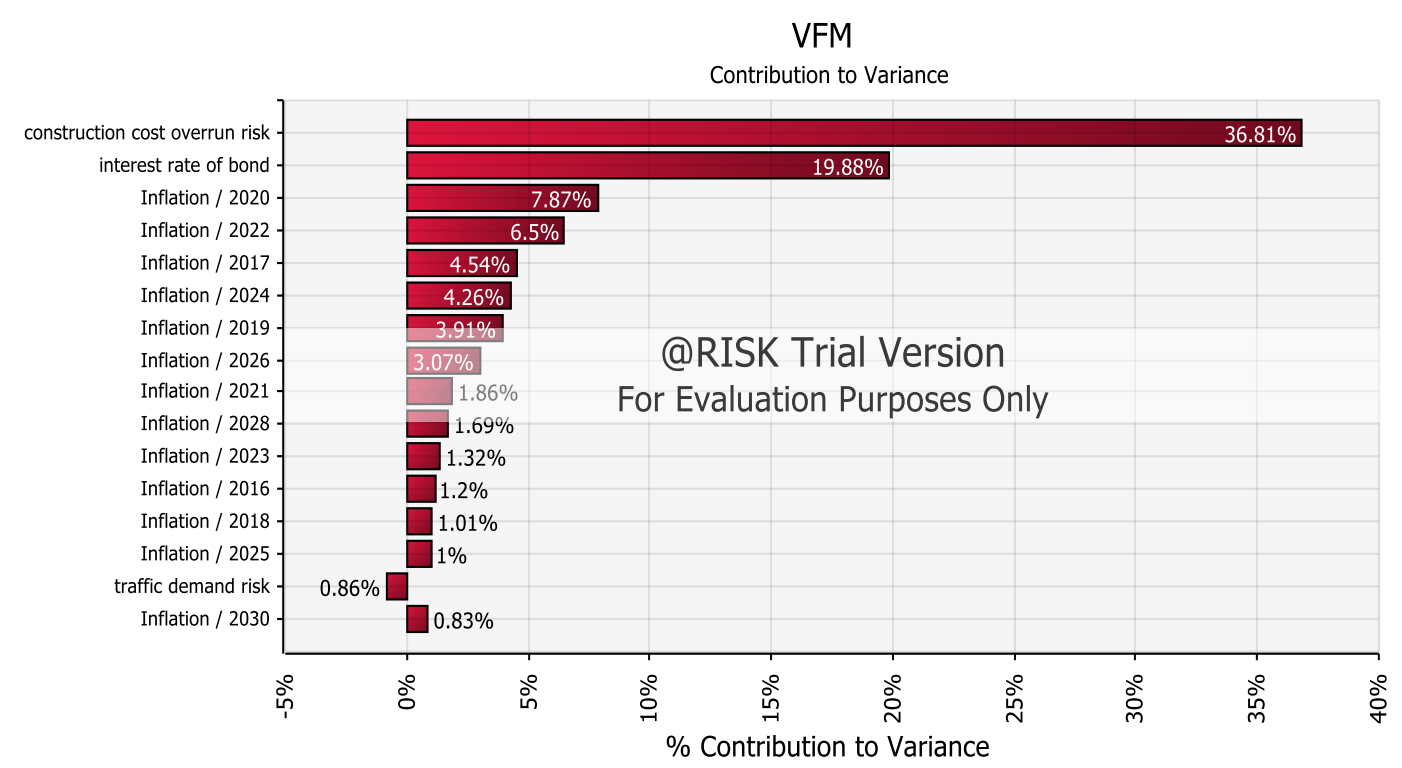

Figure 5. Sensitivity tornado graph for the project's value for money

Source: Author's result

Figure 6 confirms the relationship between construction cost inaccuracy and the simulated output of quantitative VFM. The $\mathrm{X}$-axis illustrates the construction cost overrun ratio, and the $\mathrm{Y}$-axis represents the value of the VFM. As indicated in this, assuming that construction cost overrun ratio is larger than 0.15 , the probability of VFM being positive is $32.8 \%$. In contrast, if the ratio is less than 0.15 , the probability that the VFM indicator is larger than zero is $67.1 \%$. 


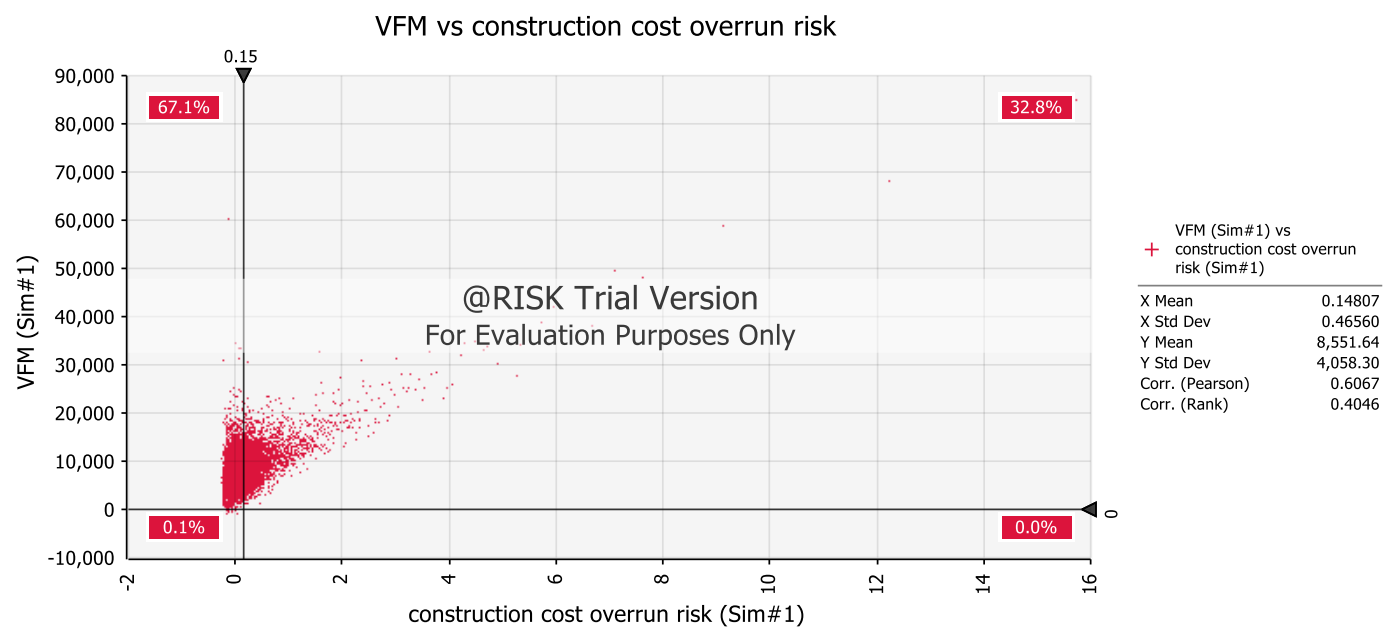

Figure 6. Scatter graph of VFM versus construction cost overrun risk

Source: Author's result

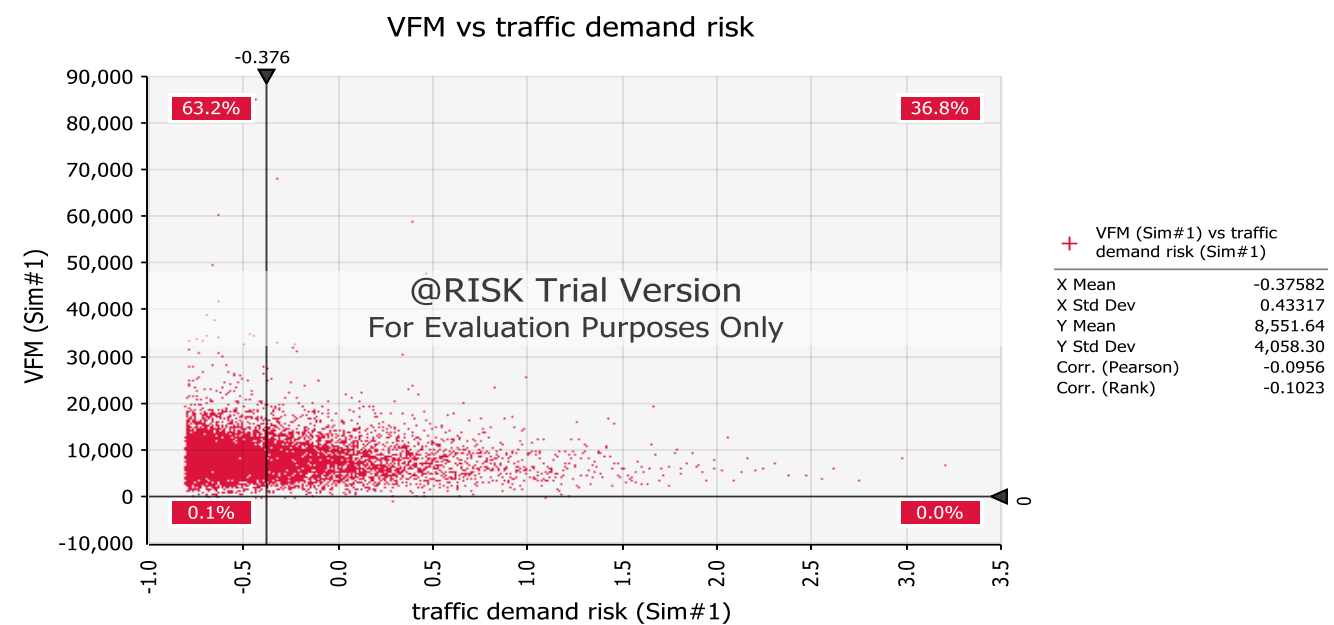

Figure 7. Scatter graph of VFM versus traffic volume risk

Source: Author's result

Figure 7 describes the relationship between traffic demand inaccuracy and the simulated VFM outcome of the Trung Luong-My Thuan case. The a-axis illustrates the traffic demand inaccuracy, and the Y-axis represents the value of the VFM outcome. As can be seen in figure 7, if there is a traffic demand inaccuracy below -0.376 , there is $63.2 \%$ confidence level that VFM is larger than zero. Otherwise, if this inaccuracy is larger than -0.376 , there is roughly a $36.8 \%$ chance that the VFM outcome is positive.

\section{CONCLUSION}

Application of the VFM assessment to the case of Trung Luong-My Thuan, combined with a sensitivity analysis and MCS reveals that decision to pursue PPP to finance the Trung Luong-My Thuan project is the right choice of the Vietnamese government. One of the reasons it leads to a high value of VFM may be that the Vietnamese government has provided revenue support for this project with a value of VND 15,488 billion. 
This research is one of very few researches to discuss the application of VFM in PPP program in Vietnam. Theoretically, a PPP project plan is approved after a VFM test and feasibility evaluation. However, in the current context of PPP program in Vietnam, the VFM assessment of PPP scheme has not been paid enough attention, most of the times none at all. Thus, this research is expected to be a significant milestone for further application in Vietnam when choosing a PPP model to finance a proposed project, in the early planning stage.

Besides the aforementioned contributions to the practical implications, limitations can also be found. The potential limitation of this research is the application of the VFM assessment combined with Monte Carlos simulation to estimate the probability of the PPP suitability to develop a project, in particular, is not always the best approach to get a general indication on the suitability of the PPP model for expressway projects in general for Vietnam. Another shortcoming of this research is the ignorance of consideration of the standpoint of qualitative assessment for this project. In order to deal with the first issue, Bootstrap method is suggested for future research to achieve this goal. For the last problem, further studies could usefully explore Multi-Criteria Decision Analysis (MCDA).

\section{REFERENCES}

Government of India. (2010). Developing Toolkits for Improving Public Private Partnership Decision Making Processes: User Guide. New Delhi: Department of Economic Affairs.

Inanmi, Yo \& Koizumi, R. (2013). Review of Sample Size for Structural Equation Models in Second Language Testing and Learning Research: A Monte Carlo Approach. International Journal of Testing, 13(4), 329-353.

Morallos, D. \& Amekudzi, A. (2008). A state of the practice of value for money analysis in comparing Public Private Partnership to traditional procurement. Public Works management Policy, 13(2), 114-125.

National Council for Public-Private Partnerships. (2012). Testing Tradition - Assessing the added value of public private partnerships. Arlington, VA: National Council for Public-Private Partnerships.

Partnerships British Columbia. (2011). Methodology for Quantitative Procurement Options Analysis Discussion Paper. British Columbia: Partnerships British Columbia.

Partnership Victoria. (2003). Use of Discount Rates in the Partnerships Victoria Process-Technical Note. Victoria: Department of Treasury and Finance.

Tsukada, S. (2015). Adoption of shadow bid pricing for enhanced application of "value for money" methodology to PPP programs. Public Works Management and Policy, 20(3), 248-263.

Tsamboulas, D., Verma, A. \& Moraiti, P. (2013). Transport infrastructure provision and operations: Why should governments choose private-public partnership. Research in Transportation Economics, 38(2013), 122-127.

United Nation Economic and Social Commision for Asia and the Pacific. (2011). A guidebook on Public-Private Partnership in infrastructure. Bangkok: ESCAP.

Vietnamese Ministry of Finance. (2013). Circular No 159/2013/TT-BTC on collection, payment, management, and use of roaduse tolls for the payback of the road construction investment capital. [Online]. Retrieved January 20, 2017 from http://www.moj.gov.vn/vbpq/lists/vn\%20bn\%20php\%20lut/view detail.aspx?itemid=29334.

World Bank. (2013). Value-for-Money Analysis Practices and Challenges: How Governments Choose When to Use PPP to Deliver Public Infrastructure and Services. Washington, DC: World Bank Group. 